\title{
A Decomposition of Shifts of the Beveridge Curve
}

\section{Rand Ghayad}

\begin{abstract}
:
The apparent outward shift of the Beveridge curve-the empirical relationship between job openings and unemployment-has received much attention among economists and policymakers in the recent years with many analyses pointing to extended unemployment benefits as a reason behind the shift. However, other explanations have also been proposed for this shift, including worsening structural unemployment.

If the increased availability of unemployment insurance (UI) benefits to the long-term unemployed is responsible for the shift in the Beveridge curve, then allowing these benefits to expire should move many of the long-term unemployed back to work (or out of the labor force).

Evidence from decomposing the job openings and unemployment relationship using data on unemployed persons by reason of unemployment shows that a significant portion of the outward shift in the Beveridge curve is concentrated among new entrants and unemployed reentrants - those generally not eligible to collect regular or extended benefits. The decomposition reveals that at most half of the shift in the aggregate Beveridge curve is attributable to the disincentive effects of unemployment benefit programs.
\end{abstract}

JEL codes: D31, D63, I32

Rand Ghayad is a visiting fellow at the Federal Reserve Bank of Boston and a Ph.D. candidate at Northeastern University. His e-mail address is ghayad.r@gmail.com.

I would like to thank William Dickens, Robert Triest, and Peter Diamond for their helpful comments and suggestions.

The views expressed in this brief are the author's and do not necessarily reflect the official position of the Federal Reserve Bank of Boston or the Federal Reserve System.

This brief, which may be revised, is available on the web site of the Federal Reserve Bank of Boston at http://www.bostonfed.org/economic/ppb/index.htm.

This version: May 2013 


\section{Introduction}

With the sharp increase in the unemployment rate during the recent recession, Congress enacted a series of unemployment insurance (UI) extensions, allowing jobless individuals to collect up to 99 weeks of benefits in some states. Even though the labor market has been improving, there are still nearly three unemployed workers for each job opening, and the average duration of unemployment is currently 40 weeks - longer than the 26 weeks of benefits that an unemployed worker is normally eligible to collect. ${ }^{1}$ With the sharp rise in the unemployment rate over the recent recession, Congress approved additional weeks of benefits by authorizing the Emergency Unemployment Compensation (EUC) program, which added up to 53 weeks of coverage to regular and extended benefits $(E B)^{2}$ for a combined total of 99 weeks in states with the highest unemployment rates.

The increased availability of unemployment compensation has been identified by many economists as an important source of the persistently high rates of unemployment. This policy brief is an extension of recent work by Ghayad and Dickens (2012) on the Beveridge curve that intends to answer more succinctly the question economists have been asking: "Will the Beveridge curve move back when unemployment benefits expire?" Evidence in the earlier policy brief confirmed that the increase in job openings relative to unemployment-depicted by the outward shift of the Beveridge curve $^{3}$ - has taken place only among the long-term unemployed, suggesting a possible role for extended UI benefits.

This brief uncovers new facts that emerge from disaggregating the unemployment rate into different categories by reason for unemployment. According to the classification scheme of the UI program, an unemployed worker's reason for unemployment is a major factor in determining whether or not the worker is eligible to collect unemployment benefits. Job losers,

\footnotetext{
${ }^{1}$ Source: U.S Bureau of Labor Statistics

${ }^{2}$ Extended benefits is a preexisting program that provides benefits beyond six months in states facing high unemployment rates.

${ }^{3}$ The Beveridge curve refers to the inverse relationship between job openings and unemployment.
} 
who are often qualified to receive unemployment benefits, constitute only about half of the total unemployed (53 percent in January 2013), while the remaining portion comprises job leavers, new entrants, and unemployed re-entrants, who are generally not eligible to receive unemployment benefits.

If part of the shift is explained by unemployed workers who are ineligible to collect benefits, then the Beveridge curve will not shift back to its pre-recession position when benefits for the long-term unemployed are discontinued.

In order to estimate which groups account for the breakdown in the vacancy and unemployment relationship, I decompose the recent deviation from the Beveridge curve into different parts, using data on job openings from the Job Openings and Labor Turnover Survey (JOLTS) and unemployed persons by reason of unemployment obtained from the Current Population Survey (CPS).

The findings put an upward bound on the extent to which the increase in unemployment relative to job openings is due to reduced search effort caused by the extended availability of unemployment insurance.

\section{The Beveridge curve}

It is standard in the literature to interpret movements along the Beveridge curve as cyclical movements in labor demand, and to interpret shifts in the Beveridge curve as indicative of shifts in the efficiency of job-worker matching. Figure 1 displays the Beveridge curve with the actual unemployment rate (total unemployed as a percentage of the labor force) on the horizontal axis and the job openings rate (imputed job openings as a percentage of the labor force) on the vertical axis, for the period starting January 2001. The solid black line-a fitted Beveridge curve-represents an estimate of the relationship between job openings and unemployment, using data through August 2009, the time before the vacancy-unemployment relationship began 
to shift outward. ${ }^{4}$ The blue dots are observations from January 2001 to August 2009. The red diamonds are observations for the subsequent months, running up to January 2013. While the blue dots show a clear, stable, downward-sloping relationship between job openings and unemployment rates up to August 2009, the deviation of the points starting in September of 2009 from the stable Beveridge curve has been attributed by many economists to factors such as a rise in the mismatch between the skills of the unemployed and the skills desired by employers, or to the supplemental and extended UI benefit programs that were designed to attenuate the hardships of involuntary job losses over the course of the Great Recession.

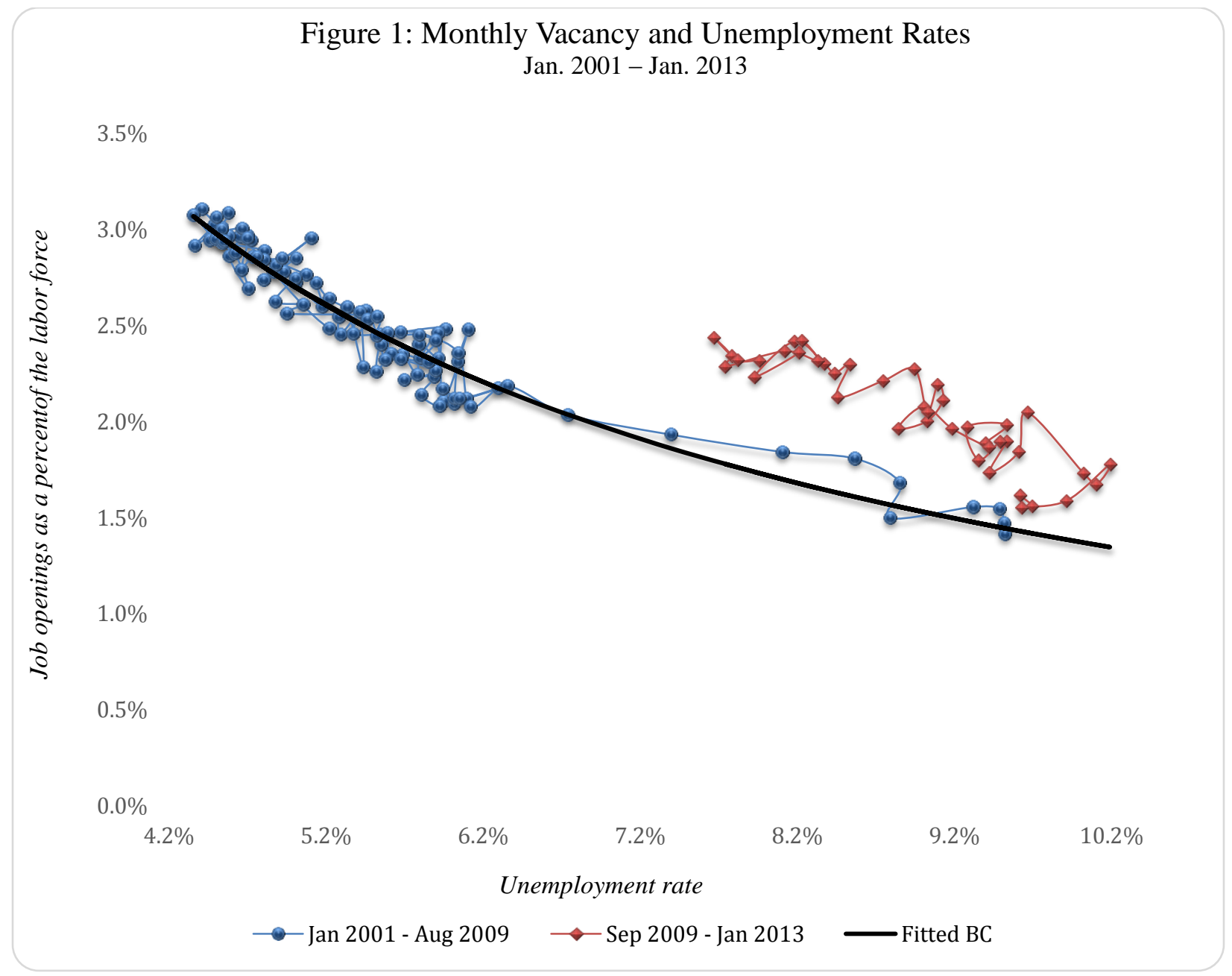

Note: The blue dots are observations for 2001:m01-2009:m08. The red diamonds are the observations for 2009:m09-2013:m01. Source: CPS and JOLTS.

\footnotetext{
${ }^{4}$ Appendix 1 explains how the Beveridge curves were estimated.
} 
Ghayad and Dickens (2012) disaggregated the job vacancy-unemployment relationship by duration of unemployment, industry, age, and education, as well as by blue- versus white-collar groups, to show a similar pattern during the recovery of increasing job openings with little or no change in unemployment across all categories except one: short-term unemployment. The relationship between job openings and unemployment for those employed less than six months remained stable, while the relationship for those unemployed more than six months showed a large increase in job openings relative to unemployment. ${ }^{5}$. A number of economists have argued that the increased availability and duration of unemployment compensation to unemployed job seekers may create adverse incentive effects that tend to extend their stay out of work, producing a shift in the curve, as depicted in Figure 1. (See Hobjin and Sahin 2012). This line of reasoning suggests that the outward shift of the Beveridge curve will be at least partially reversed once extended benefits lapse.

\section{Which groups are shifting the Beveridge curve?}

There are many reasons why individuals become unemployed, and their experiences with unemployment vary widely. The CPS divides these myriad reasons into four major categories. People become unemployed because they either lose their previous job (job losers), quit their previous job voluntarily (job leavers), enter the labor force to look for work for the first time (new entrants), or re-enter the labor force after being out of it for a while (re-entrants).

Following Valletta \& Kuang (2010), one can group data from the CPS on the unemployed by reason for unemployment into two categories: job losers, who may be eligible to collect regular and extended benefits, ${ }^{6}$ and all other unemployed persons (job leavers, new entrants to the labor force, and unemployed re-entrants), almost all of whom are ineligible to collect such benefits. Job losers are divided in the CPS into two groups: those on temporary layoff and those on a

\footnotetext{
${ }^{5}$ Rand Ghayad and William Dickens "What Can We Learn by Disaggregating the Unemployment-Vacancy Relationship?" Public Policy Brief 12-3 Federal Reserve Bank of Boston.

${ }^{6}$ Some job losers may be ineligible for unemployment benefits - for example, those who worked in jobs not covered by unemployment insurance, those with insufficient months of paid work prior to losing their job, and those who were fired for cause.
} 
permanent layoff; both are qualified to collect regular, extended, and emergency UI benefits. In contrast, unemployed persons who are job leavers, new entrants, and unemployed re-entrants are not normally eligible to collect regular or extended benefits but are classified as unemployed according to the CPS. One exception is re-entrants who were job losers before leaving and subsequently re-entering the labor force. These people may be eligible to collect unemployment benefits if they are still within their period of eligibility.

Each of the two categories of the unemployed can be expressed as a proportion of the entire civilian labor force; the sum of the two rates thus equals the unemployment rate for all civilian workers. Figures 2-3 below depict the relationship between unemployment for each group (calculated as a fraction of the entire labor force) and aggregate job openings independently. The blue dots are observations from January 2001 up to August 2009, while the red diamonds are observations from September 2009 onwards. While the increased availability of unemployment benefits to job losers may have contributed to the outward shift in the Beveridge curve (Figure 2), a similar breakdown in the vacancy and unemployment relationship is observed when the aggregate job openings rate is plotted against the fraction of the labor force combining job leavers, unemployed re-entrants, and new entrants (Figure 3). ${ }^{7}$

\footnotetext{
${ }^{7}$ A similar shift is observed if new entrants and re-entrants (as a fraction of total labor force) are plotted separately against the job openings rate. In contrast, the relationship between the job openings rate and the unemployment rate for individuals who voluntarily quit their jobs (job leavers) appears to be vertical, which tells us little about what we see in the aggregate plot.
} 


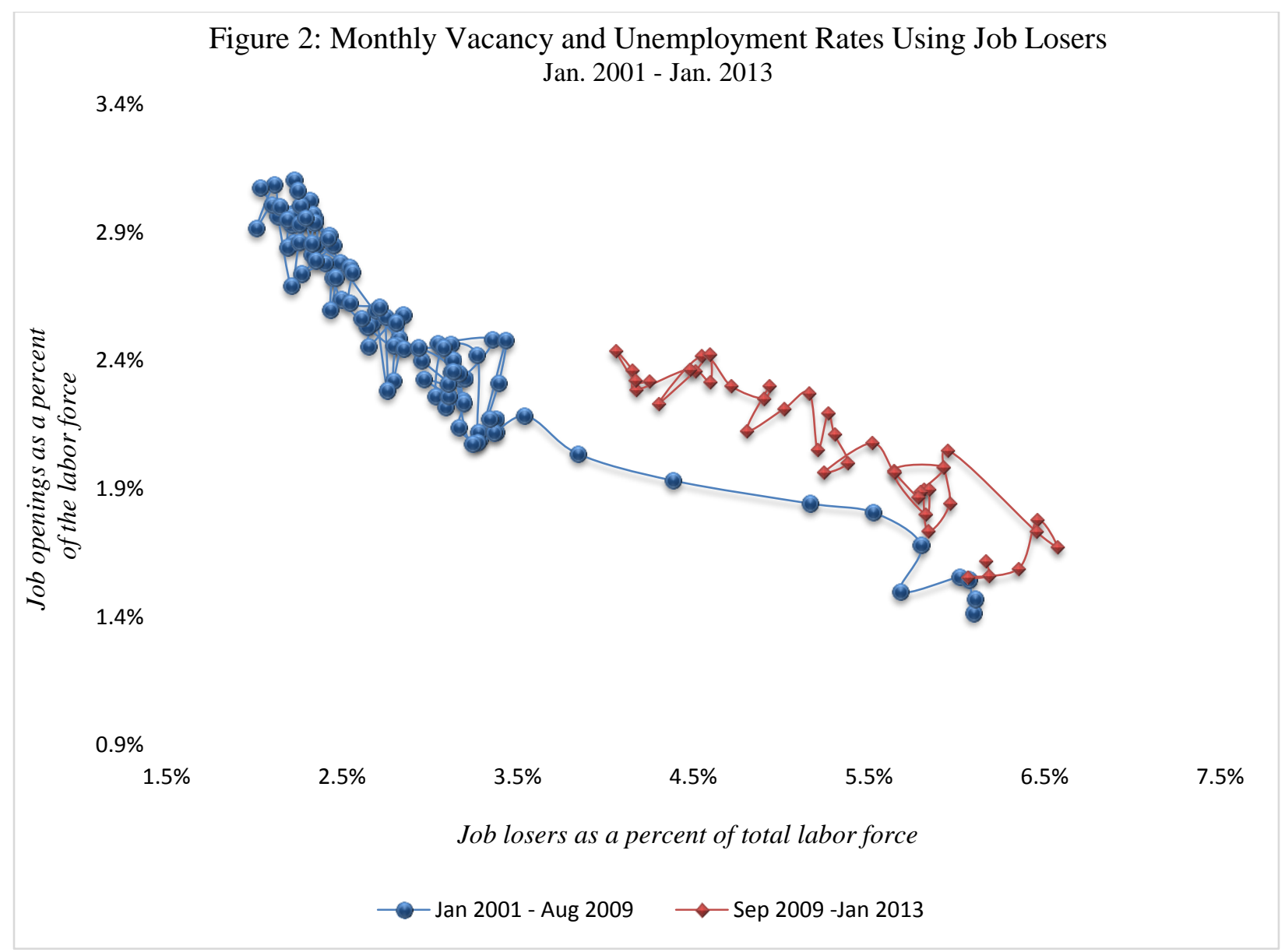

Note: The blue dots are observations for 2001:m01-2009:m08. The red diamonds are the observations for 2009:m09-2013:m01. Source: CPS and JOLTS 


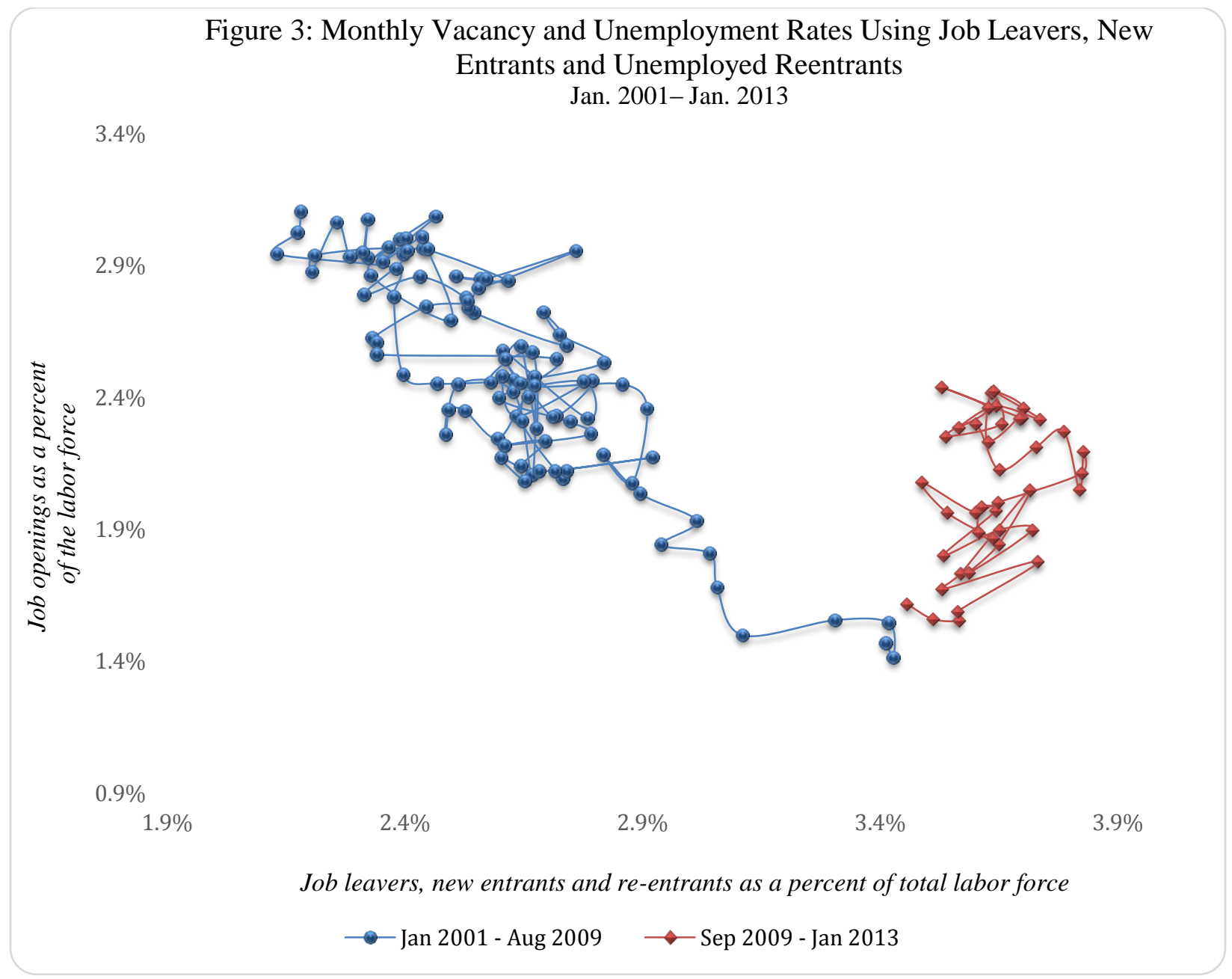

Note: The blue dots are observations for 2001:m01 -2009:m08. The red diamonds are the observations for 2009:m09- 2013:m01. Source: CPS and JOLTS.

\section{Decomposing the Beveridge curve gap:}

In this section, I decompose the aggregate Beveridge curve gap to estimate the contribution of the different unemployment categories to the deviation of the vacancy and unemployment rates from their historical empirical estimation. The decomposition is merely an accounting exercise and the monthly shares of each group are reported in the table of Appendix 2.

Figure 4 plots the actual job openings and unemployment rates and fits a Beveridge curve using data through August 2009. The estimated Beveridge curve fits the data well up to August 2009. However, after 2009 the unemployment rate is consistently above what would be expected 
given the old Beveridge curve. For example, given the September 2009 job openings rate, the actual unemployment rate was 1.10 percentage points above the one implied by the fitted curve. I refer to this deviation as the Beveridge curve gap.

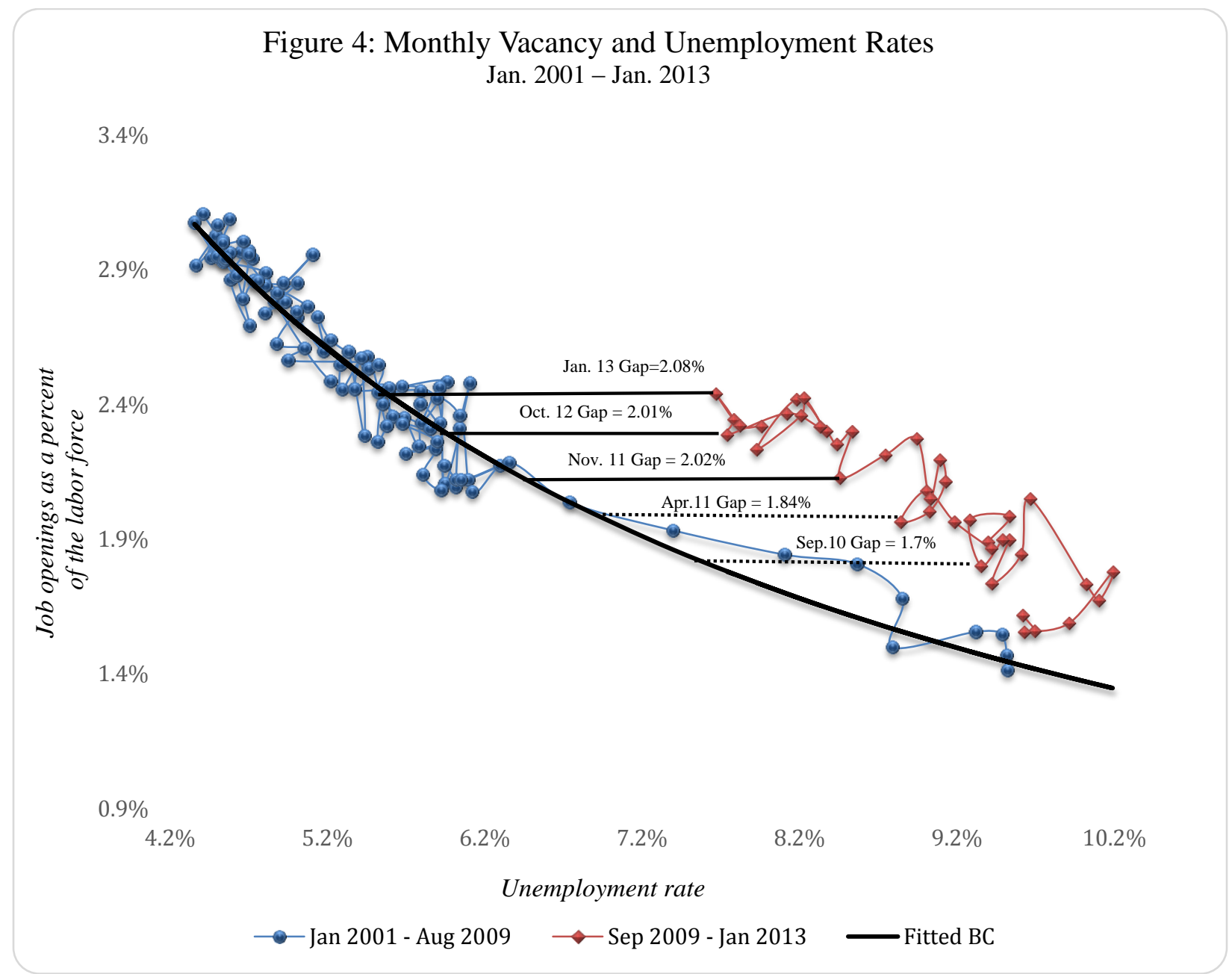

Note: The blue dots are observations for 2001:m1-2009:m08. The red diamonds are the observations for 2009:m09-2013:m01. The black curve is a fitted estimation using data prior to September 2009. For a given job openings rate, the gap is calculated by measuring the deviation of the actual unemployment rate from that implied by the fitted curve. Source: CPS and JOLTS.

In Figures 5 and 6 below, I use a similar method to fit empirical Beveridge curves for job leavers, new entrants, and re-entrants (Figure 5), as well as job losers (Figure 6). In each figure, I estimate the deviation in the unemployment rate of each group from its fitted curve for the 
period September 2009 onwards. ${ }^{8}$ A rough calculation suggests that job leavers, new entrants, and unemployed re-entrants - most of whom are not eligible for unemployment benefits - have contributed approximately 48.5 percent of the aggregate gap in January 2013, while job losers accounted for the remaining part during the same month (Figure 7). ${ }^{9}$ While the vacancy and unemployment relationship appears to have shifted outward for job losers and unemployed entrants, exploring the relationship of each group across different age cohorts (Appendix 3) reveals that most of the shift among job losers is concentrated among persons above 44 years of age. When the job openings rate was plotted versus job losers in the following age ranges: 16-19, 20-24, 25-34, and 35-44 years as a percentage of the total labor force, there was little or no change in the historical Beveridge curve relationship (Appendix 3). This suggests that job losers younger than 45 years of age benefitted more than the older cohorts from the increase in job openings over the recent period. In contrast, exploring the relationship across different age groups using new labor market entrants, and unemployed re-entrants reveals an outward shift among all categories.

\footnotetext{
${ }^{8}$ The decomposition is merely an accounting exercise where the aggregate unemployment rate is decomposed into different categories based on CPS data for unemployed persons by reason of unemployment.

Appendix 1 provides the mathematical details on estimating fitted Beveridge curves.

${ }^{9}$ Each fraction is calculated by dividing the BC gap for that group by the total BC gap.
} 


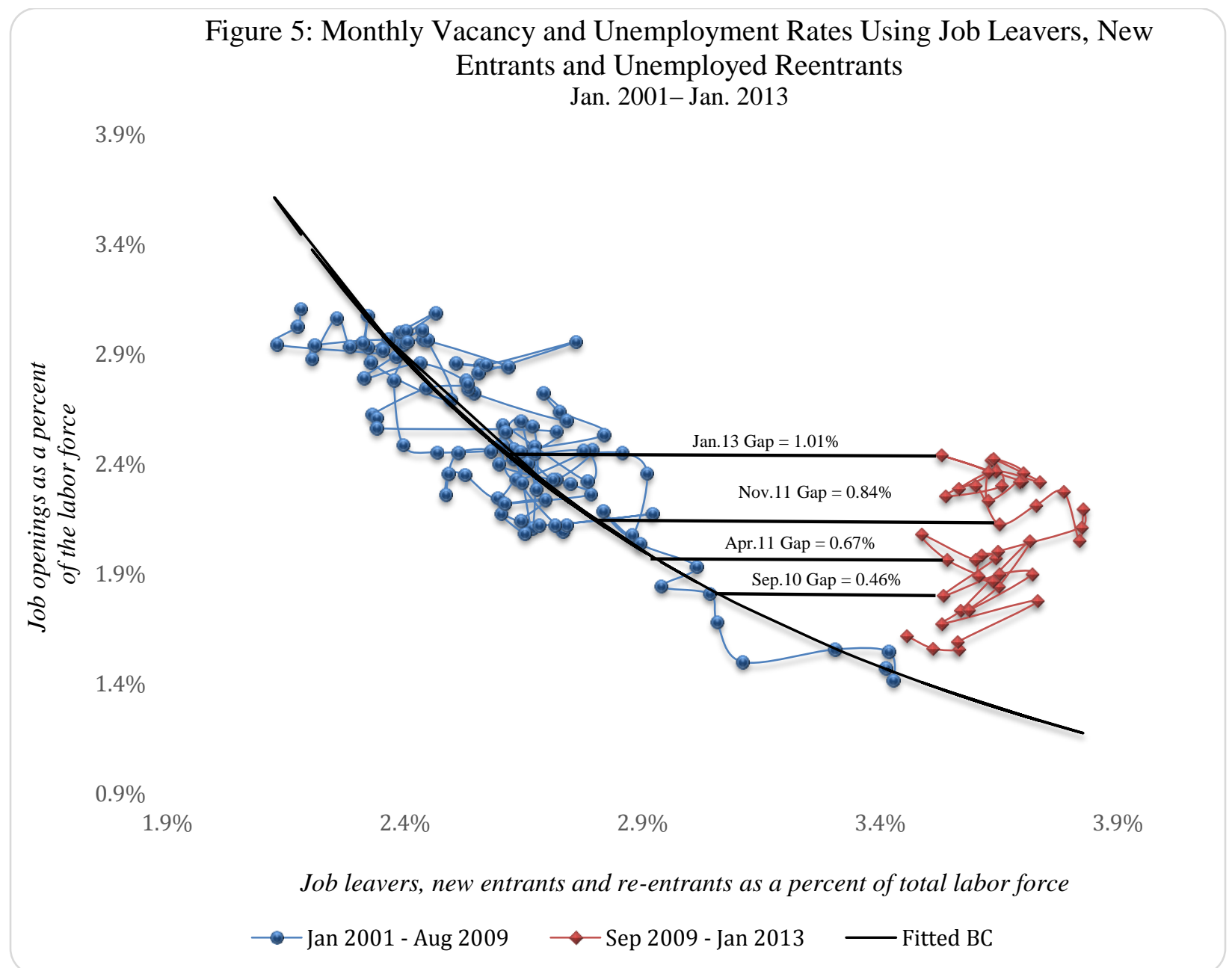

Note: The graph plots the job openings rate versus the unemployment rate using job leavers, new entrants, and re-entrants. The blue dots are the observations for 2001:m1-2009:m09. The red diamonds are the observations for 2009:m09-2013:m01. Data are seasonally adjusted monthly rates. The black curve is a fitted estimation using data prior to September 2009. For a given job openings rate, the gap is calculated by measuring the deviation of the actual unemployment rate from that implied by the fitted curve. Source: CPS and JOLTS. 


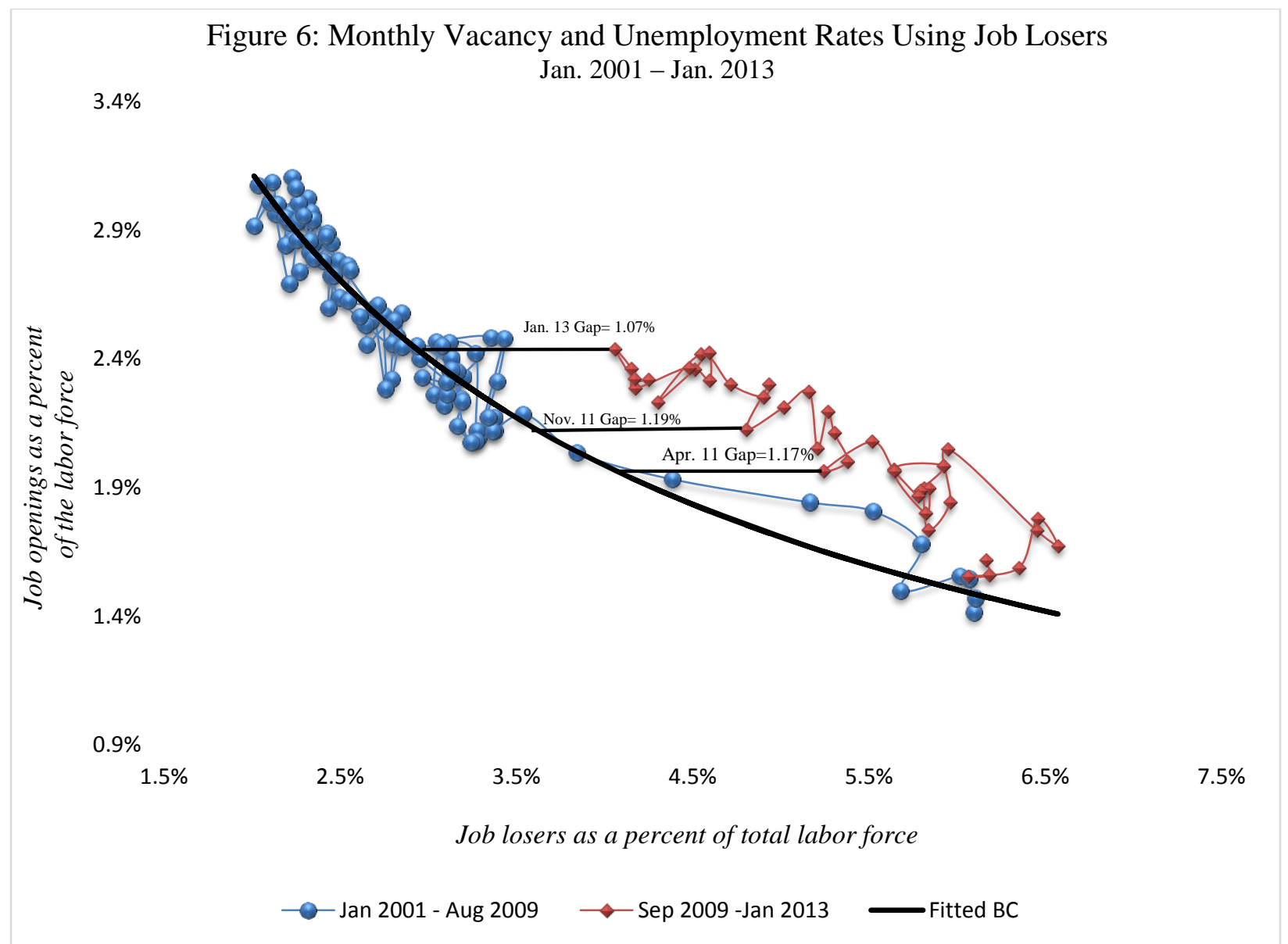

Note: The graph plots the vacancy rate versus job losers as a fraction of the entire labor force. The blue dots are the observations for 2001:m1-2009:m08. The red diamonds are the observations for 2009:m09-2013:m01. Data are seasonally adjusted monthly rates. The black curve is a fitted estimation using data prior to September 2009. For a given vacancy rate, the gap is calculated by measuring the deviation of the actual unemployment rate from that implied by the fitted curve.

Source: CPS and JOLTS. 


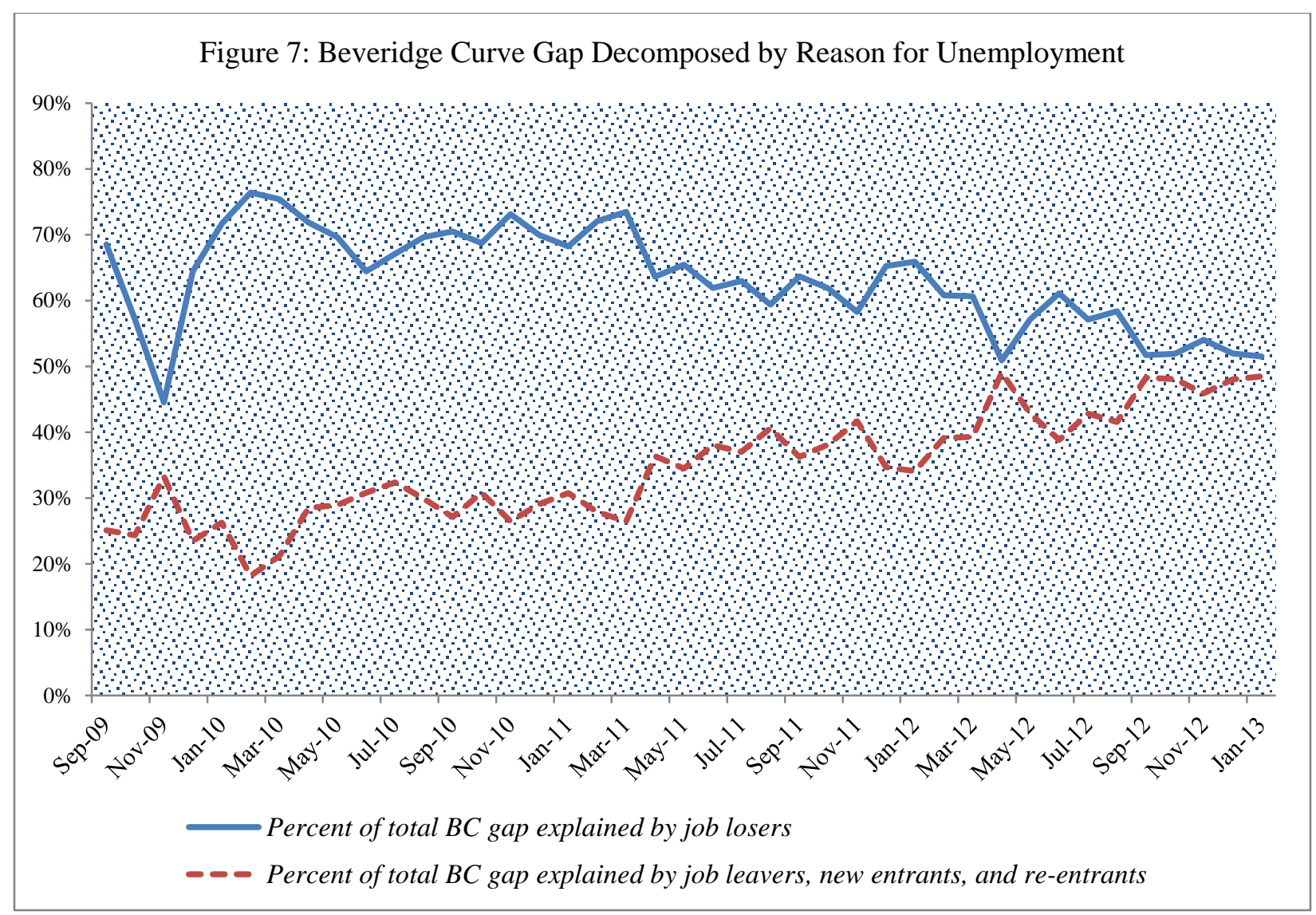

Source: author's calculations.

The residual unexplained gap is due to measurement error.

\section{Conclusion:}

Exploration of the evolution of job openings and unemployment using recent data on unemployed persons decomposed by their reason for unemployment, which determines their eligibility to collect benefits, suggests that up to half of the increase in the unemployment rate relative to the fitted Beveridge curve is explained by job leavers, new entrants, and re-entrantsthose who are ineligible to collect unemployment benefits.

Because unemployed job seekers who do not qualify to receive benefits compete for jobs with unemployed job losers who are eligible to collect UI, an unattractive vacancy that is refused by a job loser is likely be grabbed quickly by a new entrant or unemployed re-entrant who is not subject to any incentive effects. However, the evidence from the decompositions suggests that 
the increase in the unemployment rate relative to job openings will persist when unemployment benefit programs expire. 


\section{References}

Ghayad, Rand and William T. Dickens. 2012. "What Can We Learn by Disaggregating the Unemployment-Vacancy Relationship?" Federal Reserve Bank of Boston Public Policy Brief 123.

Hobjin, Bart and Ayşegül Şahin. 2012. "Beveridge Curve Shifts Across Countries Since the Great Recession." working paper presented at the $13^{\text {th }}$ Jacques Polak Annual Research Conference, November 8-9, 2012.

Valletta, Robert G., and Katherine Kuang. 2010b."Is Structural Unemployment on the Rise?" FRBSF Economic Letter 2010-34, Federal Reserve Bank of Francisco. 


\section{Appendix 1: Mathematical and data details}

To estimate the Beveridge curve, I regress $\ln \left(\frac{1-u}{u}\right)$ on $\ln \left(\frac{v}{u}\right)$.

We can write (1) as

$$
\ln \left(\frac{1-u}{u}\right)=a+b \ln \left(\frac{v}{u}\right)+\varepsilon
$$

$$
e^{\ln \left(\frac{1-u}{u}\right)}=e^{a} * e^{b \ln \left(\frac{v}{u}\right)}
$$

This simplifies to

$$
\left(\frac{1-u}{u}\right)=e^{a} *\left(\frac{v}{u}\right)^{b}
$$

Re-arranging

$$
\begin{gathered}
u^{b-1}-u^{b}-e^{a} * v^{b}=0 \\
v=\left(\frac{u^{b-1}-u^{b}}{e^{a}}\right)^{\frac{1}{b}}
\end{gathered}
$$

This relationship is used to plot the Beveridge curve in Figures 1 and $4-6$ and is used to compute the expected unemployment rate for a given vacancy rate in the table in Appendix 2. 


\section{Appendix 2:}

\begin{tabular}{|c|c|c|c|}
\hline \multicolumn{4}{|c|}{$\begin{array}{c}\text { Deviations of Unemployment Rates from their Fitted Values for Job Losers, } \\
\text { Job Leavers, New Entrants, and Unemployed Re-entrants }\end{array}$} \\
\hline Date & BC Gap using Job Losers & $\begin{array}{c}\text { BC Gap using Job Leavers, New Entrants, } \\
\text { and Re-entrants }\end{array}$ & BC Gap using Total Unemployed \\
\hline Sep-09 & $0.75 \%$ & $0.28 \%$ & $1.10 \%$ \\
\hline Oct-09 & $0.49 \%$ & $0.21 \%$ & $0.87 \%$ \\
\hline Nov-09 & $0.34 \%$ & $0.26 \%$ & $0.77 \%$ \\
\hline Dec-09 & $0.80 \%$ & $0.29 \%$ & $1.24 \%$ \\
\hline $\operatorname{Jan}-10$ & $1.75 \%$ & $0.64 \%$ & $2.44 \%$ \\
\hline Feb-10 & $1.42 \%$ & $0.34 \%$ & $1.86 \%$ \\
\hline Mar-10 & $1.56 \%$ & $0.44 \%$ & $2.07 \%$ \\
\hline Apr-10 & $2.13 \%$ & $0.84 \%$ & $2.96 \%$ \\
\hline May-10 & $1.49 \%$ & $0.62 \%$ & $2.14 \%$ \\
\hline Jun-10 & $0.96 \%$ & $0.46 \%$ & $1.48 \%$ \\
\hline Jul-10 & $1.53 \%$ & $0.74 \%$ & $2.28 \%$ \\
\hline Aug-10 & $1.56 \%$ & $0.67 \%$ & $2.24 \%$ \\
\hline Sep-10 & $1.20 \%$ & $0.46 \%$ & $1.70 \%$ \\
\hline Oct-10 & $1.59 \%$ & $0.71 \%$ & $2.31 \%$ \\
\hline Nov-10 & $1.91 \%$ & $0.69 \%$ & $2.62 \%$ \\
\hline Dec-10 & $1.48 \%$ & $0.62 \%$ & $2.12 \%$ \\
\hline Jan-11 & $1.39 \%$ & $0.63 \%$ & $2.04 \%$ \\
\hline Feb-11 & $1.57 \%$ & $0.61 \%$ & $2.18 \%$ \\
\hline Mar-11 & $1.78 \%$ & $0.64 \%$ & $2.41 \%$ \\
\hline Apr-11 & $1.17 \%$ & $0.67 \%$ & $1.84 \%$ \\
\hline May-11 & $1.42 \%$ & $0.75 \%$ & $2.16 \%$ \\
\hline Jun-11 & $1.65 \%$ & $1.00 \%$ & $2.64 \%$ \\
\hline Jul-11 & $1.82 \%$ & $1.06 \%$ & $2.85 \%$ \\
\hline Aug-11 & $1.40 \%$ & $0.95 \%$ & $2.34 \%$ \\
\hline Sep-11 & $1.89 \%$ & $1.07 \%$ & $2.94 \%$ \\
\hline Oct-11 & $1.62 \%$ & $0.98 \%$ & $2.56 \%$ \\
\hline Nov-11 & $1.19 \%$ & $0.84 \%$ & $2.02 \%$ \\
\hline Dec-11 & $1.72 \%$ & $0.90 \%$ & $2.59 \%$ \\
\hline Jan-12 & $1.59 \%$ & $0.81 \%$ & $2.37 \%$ \\
\hline Feb-12 & $1.50 \%$ & $0.96 \%$ & $2.44 \%$ \\
\hline Mar-12 & $1.58 \%$ & $1.00 \%$ & $2.55 \%$ \\
\hline Apr-12 & $0.94 \%$ & $0.89 \%$ & $1.81 \%$ \\
\hline May-12 & $1.42 \%$ & $1.04 \%$ & $2.43 \%$ \\
\hline Jun-12 & $1.63 \%$ & $1.02 \%$ & $2.62 \%$ \\
\hline Jul-12 & $1.42 \%$ & $1.05 \%$ & $2.44 \%$ \\
\hline Aug-12 & $1.41 \%$ & $0.98 \%$ & $2.36 \%$ \\
\hline Sep-12 & $0.94 \%$ & $0.85 \%$ & $1.77 \%$ \\
\hline Oct-12 & $1.07 \%$ & $0.98 \%$ & $2.01 \%$ \\
\hline Nov-12 & $1.13 \%$ & $0.96 \%$ & $2.09 \%$ \\
\hline Dec-12 & $1.01 \%$ & $0.93 \%$ & $1.94 \%$ \\
\hline $\operatorname{Jan}-13$ & $1.07 \%$ & $1.01 \%$ & $2.08 \%$ \\
\hline
\end{tabular}




\section{Appendix 3:}

In each graph, I split the vacancy and unemployment points into two parts: blue dots corresponding to observations up to August 2009 and red diamonds for observations from September 2009 onwards.

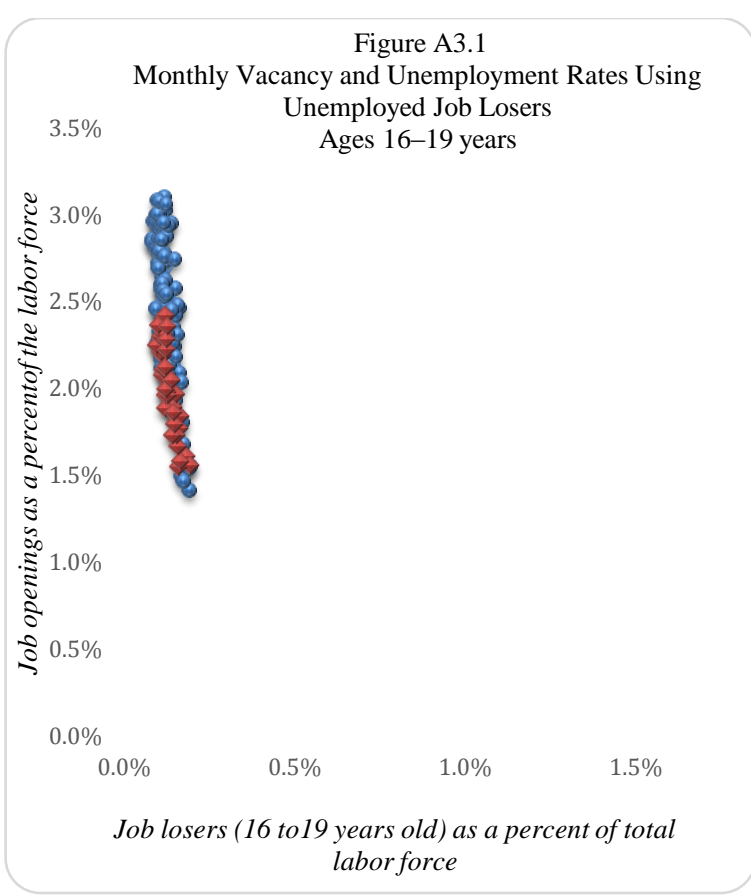

Source: CPS and JOLTS.

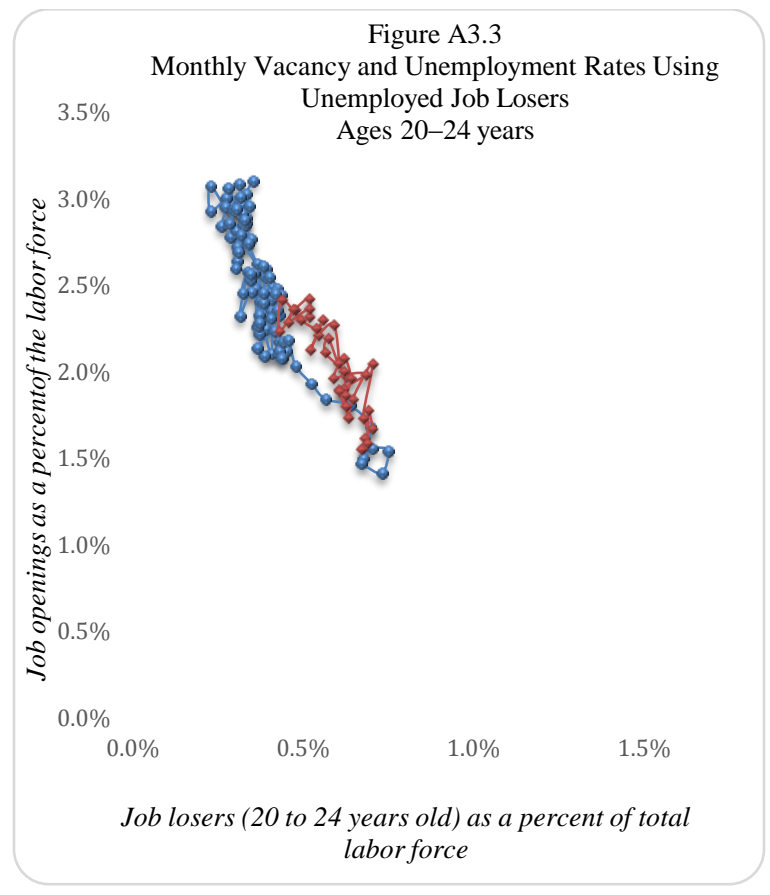

Source: CPS and JOLTS.

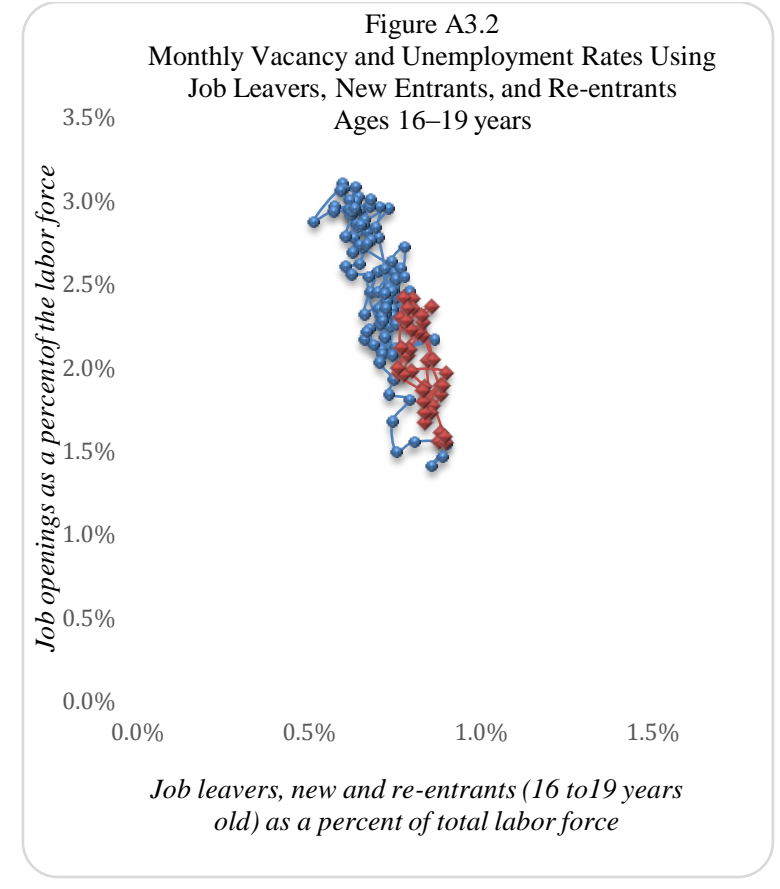

Source: CPS and JOLTS.

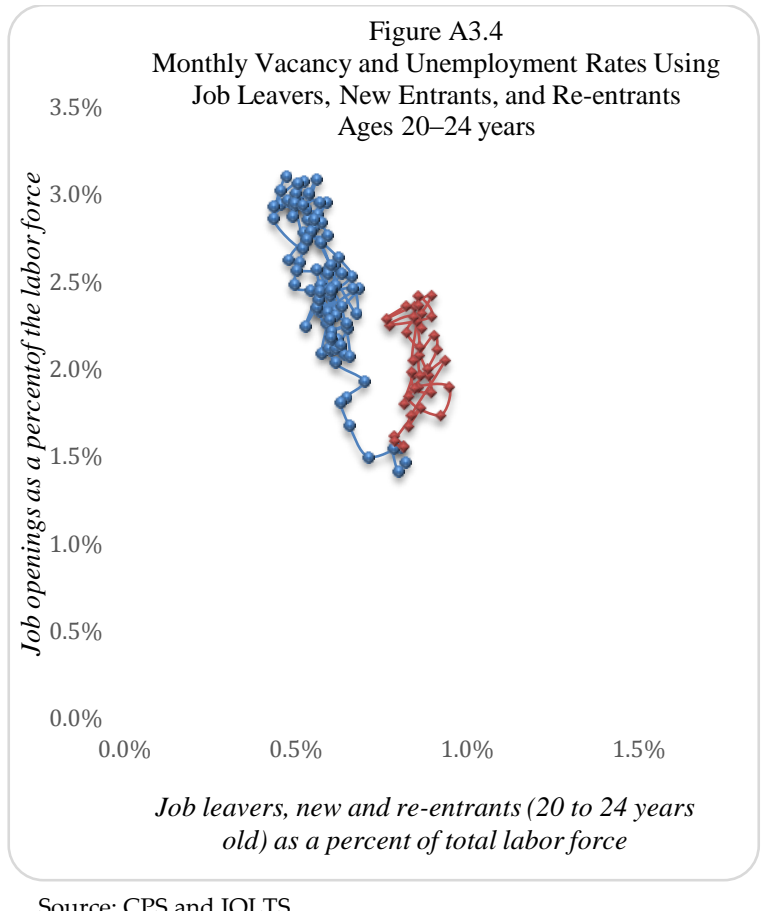

Source: CPS and JOLTS. 


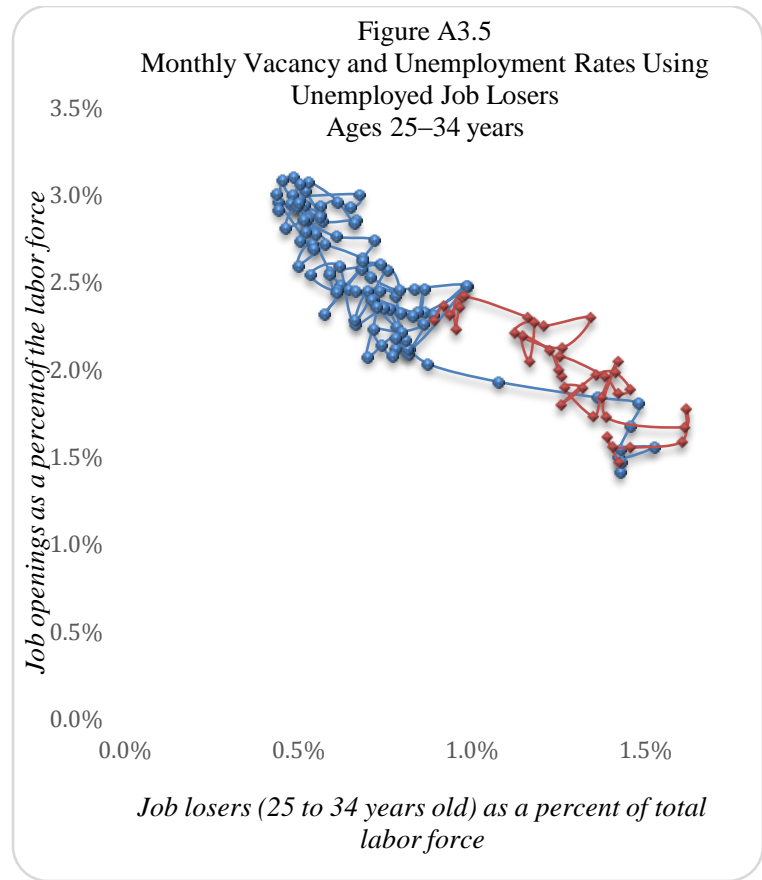

Source: CPS and JOLTS.

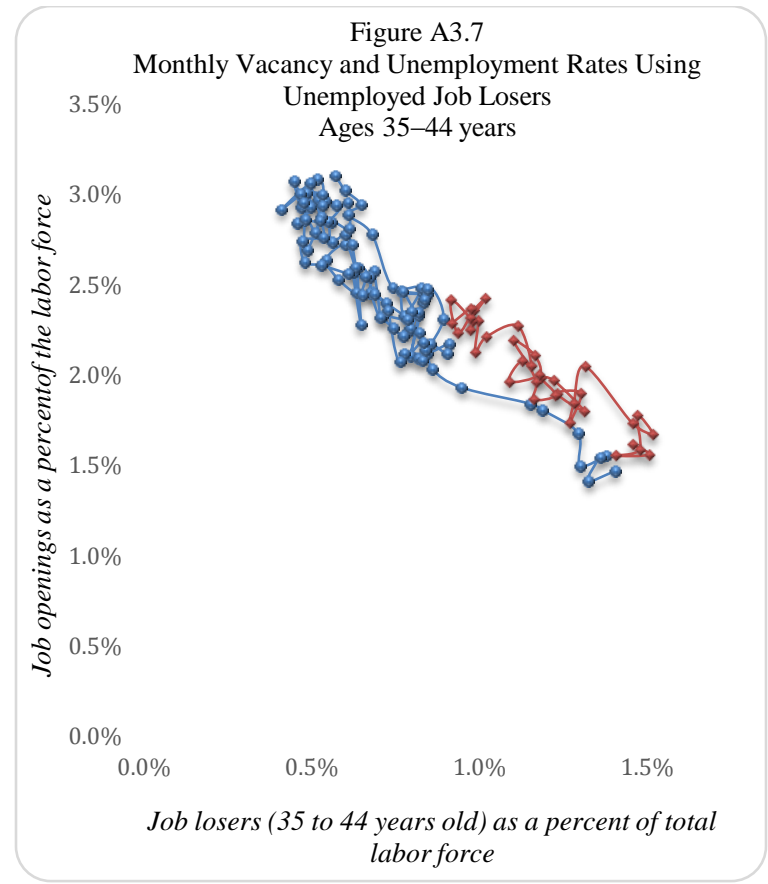

Source: CPS and JOLTS.

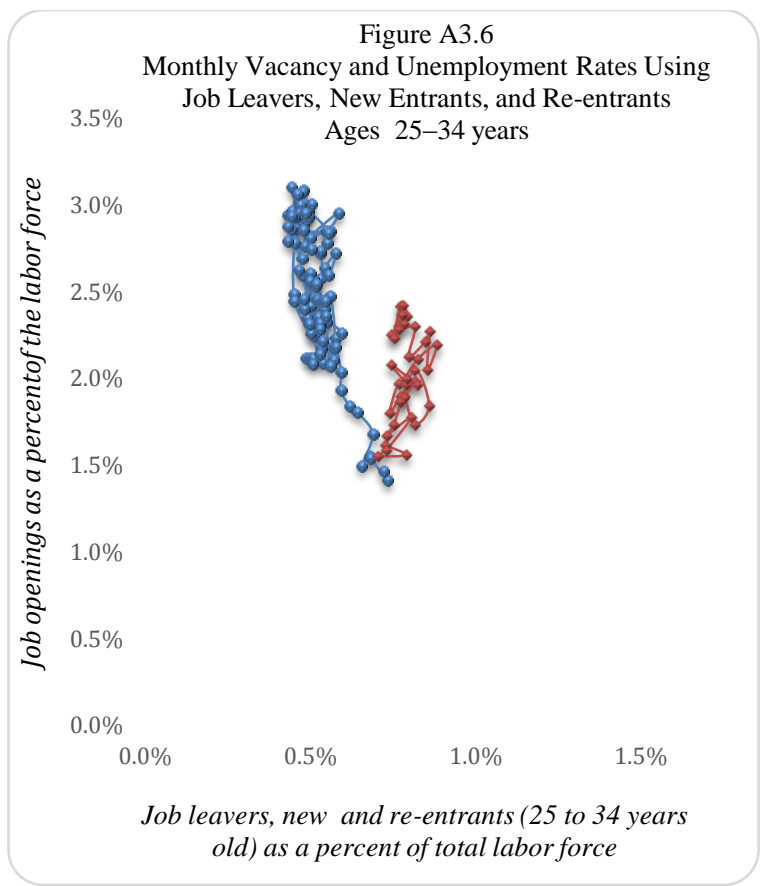

Source: CPS and JOLTS.

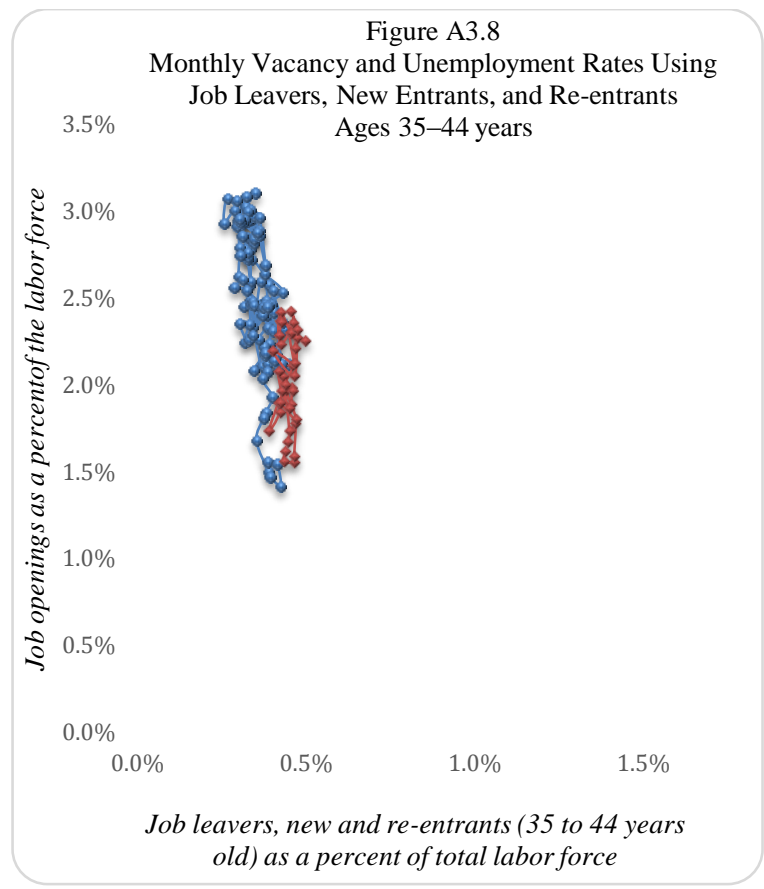

Source: CPS and JOLTS. 


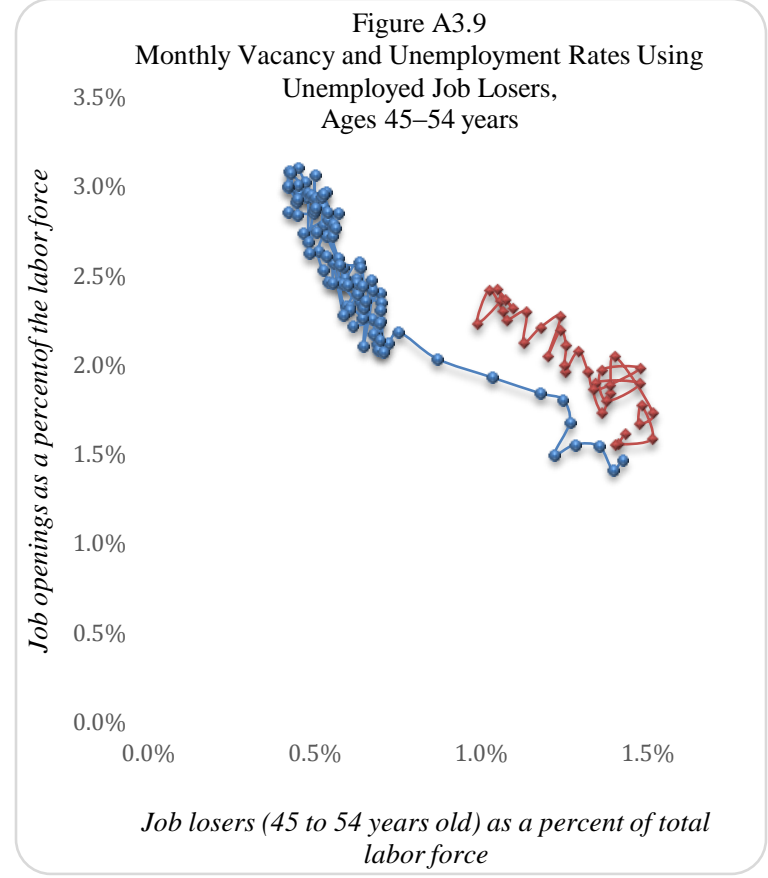

Source: CPS and JOLTS.

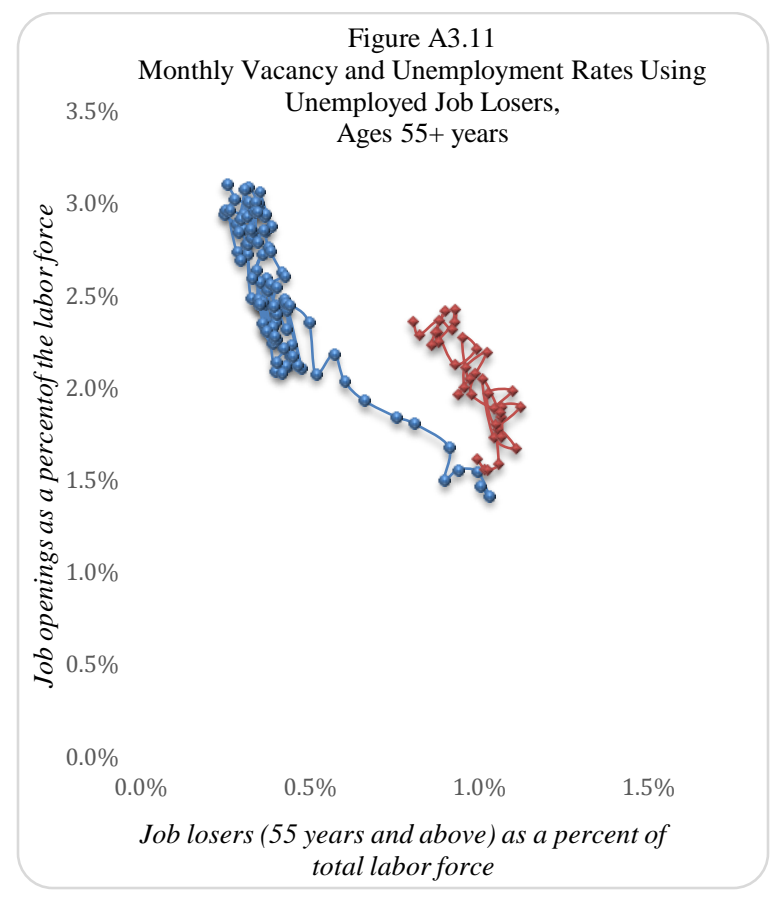

Source: CPS and JOLTS.
Figure A3.10

Monthly Vacancy and Unemployment Rates Using Job Leavers, New Entrants, and Re-entrants, Ages 45-54 years

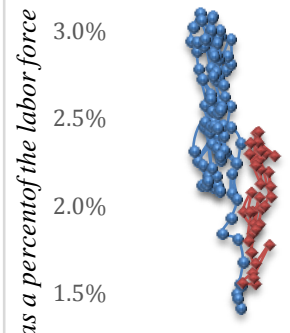

ริ

$\stackrel{\text {. }}{.} 1.0 \%$

ฐั

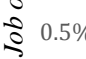

$0.0 \%$

$\begin{array}{llll}0.0 \% & 0.5 \% & 1.0 \% & 1.5 \%\end{array}$

Job leavers, new and re-entrants (45 to 54 years old) as a percent of total labor force

Source: CPS and JOLTS.

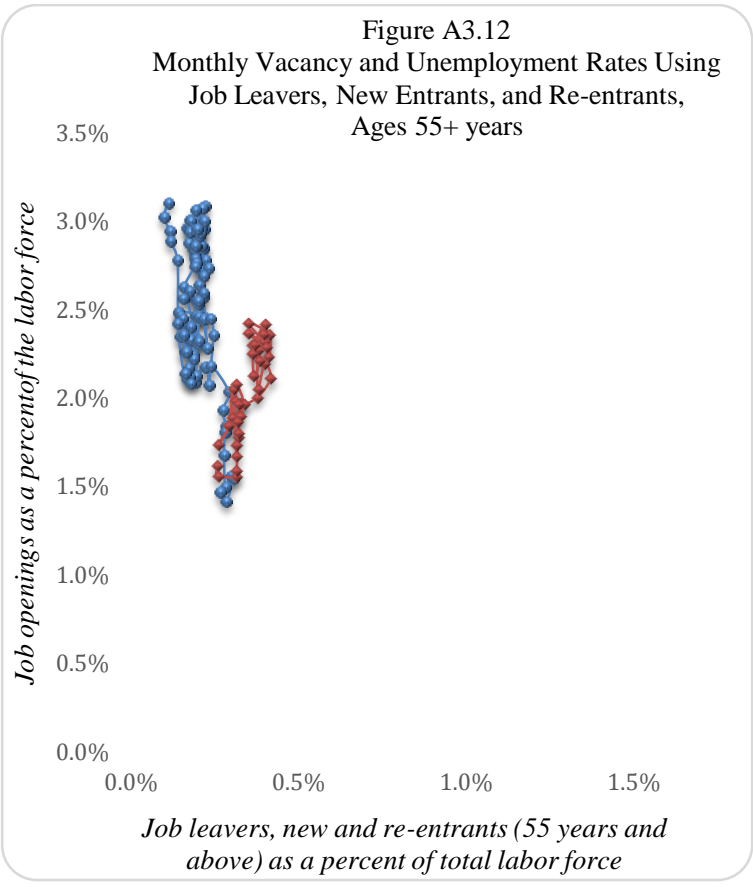

Source: CPS and JOLTS. 